\title{
Trinity: A New Education Model of Innovation and Entrepreneurship of
}

\section{College Students}

\author{
Shengguang Yan ${ }^{1, a}$, Lijuan $\mathrm{He}^{2, \mathrm{~b}}$ \\ ${ }^{1}$ North China University of Science and Technology, Tangshan City, Hebei Province, China, \\ 063000 \\ ${ }^{2}$ Kailuan General Hospital, Tangshan City, Hebei Province, China, 063000 \\ a email: \\ b email:
}

Keywords: College Students, Education of Innovation and Entrepreneurship, New Model, Team Construction of Tutor, Fund Operation, Platform Construction

\begin{abstract}
The education of innovation and entrepreneurship in our country is still in primary stage, and its police is not perfect. The teacher team need to be strengthened, and the teaching content should be improved. On the basis of the author' s own teaching practice, the thesis puts forth the "trinity" model, that is, the team construction of tutor, fund operation and platform construction. Trough the new model, the education of innovation and entrepreneurship of college students can break common dilemma and finally achieve a development of innovation and entrepreneurship education from traditional model of teaching to innovation of mechanism.
\end{abstract}

\section{Introduction}

It confirms to both national education development strategies and the trend of the times in vigorously promoting the entrepreneurship education and self-employment of college students. It is a major initiative of continuously promoting college students' employment competitiveness and the potential of sustainable development and it has a great time significance to actively carry out the education of innovation and entrepreneurship as well as encourage and support their self-employment. The "trinity" model in innovation and entrepreneurship of college students consists of team construction of tutor, fund operation of innovation and entrepreneurship and platform construction of innovation and entrepreneurship. Thereinto, the basis of innovation and entrepreneurship is team construction of tutor, the guarantee is fund operation of innovation and the support is platform construction.

\section{The Teaching Troop Construction to Build an "Engineered" Teaching Troop}

As a man disseminating knowledge and guiding ideology to college students, teacher plays a key role to higher education and developing students' abilities. Therefore, only equipping teachers with advanced the ideology and ability of innovation and entrepreneurship is it possible to develop the students with ability of innovation and entrepreneurship. At present, the majority of colleges have no professional teachers of innovation and entrepreneurship course, instead of teaching it by the college executive staff for part-time teachers. Part-time teachers usually have a lot of their own 
work to do, so it causes the curriculum fragmented, the teaching main theme not systematic and teaching methods disconnected. The Yale Report, which had an effect on teaching methods of United State in $19^{\text {th }}$ century pointed out that the aims of college education is to provide broad general basis rather than to create an expert in a certain field. It confirmed the dominant of basic education fundamentally and denied individual cultivation of selective course. In 1930s, Harvard University substantially modified the existing teaching courses and models according pros and cons of teaching, and raised a "concentration and distribution" of elective system. On the other hand, to build up a tutor mentoring can give students proper lead and guide, also to prevent them from take other non-business-related electives excessively. Thereby, it can balances the relationship between normal teaching arrangement in college and the freedom of elective courses in students.

This shows that a good construction of teaching staff is the basis of carrying out the education of innovation and entrepreneurship in college. Today, the higher education also facing the multipolar situations like "the common demands of all students ", "individual demands of most students" and "specialty developing demands of minority of students". Especially in engineering majors, an "engineered" teaching troop is the key to achieving its talents cultivating objective of innovation and entrepreneurship. The production- learning- research integration construction mode of collaborative innovation could be much more closely combined "research ideas of universities" and "production thought of enterprises" into integration. And it also can guarantee the construction of teaching troops with quality of "teacher+engineer" which the education of innovation and entrepreneurship requires. Through the platform of collaborative innovation to training a specialized teaching troop of education of innovation and entrepreneurship. To provide entitative projects like pioneer park and high-tech industry cluster to encourage teachers to participate in training by enhanced cooperation. It could utilize social resources to absorb the talents with entrepreneurial experiences and academic backgrounds engage in part-time teaching, and also could employ entrepreneurs and successful entrepreneurial alumnus as visiting professor, they can participate in the entrepreneurship program in college to communicate and guide with students face to face, through holding academic reports, joining case discussion, opening entrepreneurial class, as judge of entrepreneurial competitive and so on. For the requirements such as the capacity of innovation, psychological quality and professional knowledge which need college students contained in innovation and entrepreneurship, it should employ the entrepreneurial alumnus, the experts of psychological training and professional teachers give students professional guidance.

\section{Guaranteed on Fund Operation to Complete the Education Service System of Innovation and Entrepreneurship}

It is a process that translate theoretical idea into entrepreneurship practice, and it needs common concerns and supports of college and social resources. The principle channel of college students' innovation and entrepreneurship funds are government funding, subsidies, enterprise's venture investment, social donations, small loans and special support funds from college. To set up an all-embracing innovation and entrepreneurship fund for college students, besides, establish related fund management committee and evaluation commission. In order to ensure the operation of program funds, they need verify and project the entrepreneurial program of students and also introduce related funding declaration of innovation and entrepreneurship, and improve check mechanism through evaluating in middle term, checking in project closure and authenticating achievement project. In addition, to draw out a certain amount from the profits of technological achievements which transformed from funding programs as follow-up funding and to strengthen the cooperation with the enterprises to build up a perfect margin and investment system. 
Completing entrepreneurial services for college students, and providing mediation service, platform of enterprises financing as well as guaranteed small loans; taking full use of government support policy and providing credit guarantees and financial advisory services for college students; rendering free services of labor security and personnel agent for the companies who employed the students; implementing the corresponding preferential policies like social security benefits and tax breaks; establishing related competitive mechanism, constraint mechanism, coordination mechanism and incentive mechanism. After "211 projects" and "985 projects", China' s higher education system started the third national project, namely innovation ability promoting plant of higher education or "2011 plan". This is another huge strategic decision for our higher education stepping into a internal development, and it is significant to raise higher education' s innovation ability and ensure the educational fund of innovation and entrepreneurship. Local governments also give lots of policy subsidies like tax break to the college graduates in the first two years of entrepreneurship. And venture capital firms of "Vans Trophy" business plan competition offered great financing supports to college students as well as the colleges, both they vigorously rendered secured funding to innovation and entrepreneurship of college students.

\section{Taking the Platform Construction as Support to Create Campus Culture with Characteristics of Innovation and Entrepreneurship}

Building an education platform of innovation and entrepreneurship of resource sharing, educational cooperation and ability progression, through the platforms such as innovation and entrepreneurship course platform, innovation and entrepreneurship practice platform, innovation and entrepreneurship competition platform and campus culture activity platform with characteristics of innovation and entrepreneurship, to promote students' innovation and entrepreneurship quality and ability become an upward spiral. Innovation and entrepreneurship course platform centers on the cultivation of entrepreneurship ability and innovation spirit to offer courses of innovation and entrepreneurship knowledge and modular of capacity. The courses main including the innovation methods and innovate implementation and also including management, marketing, finance, law, public relations and social etiquette. Through pioneer park, high-tech industry cluster and college-enterprise cooperation base, innovation and entrepreneurship practice platform established a long-standing fund and incubation mechanism. Innovation and entrepreneurship competition platform arrange students take part in all kinds of design competition of Innovation and entrepreneurship in collage, like "Van Trophy" business plan competition, making and invention competition, "Science Park Trophy" scientific and technological competition and mathematical modeling competition to promote learning and communing. Building a campus culture activity platform with characteristics of innovation and entrepreneurship and setting up related innovation and entrepreneurship communities for collage students. Organizing regular activities such as "entrepreneurship" forum, academic reports, "alumni entrepreneurship" experience sharing session to strengthen training students' scientific realistic spirit, team cooperation spirit, dedication spirit and constructing active campus culture of innovation and entrepreneurship. Carefully summarizing and communicating the experience and the success of competitions in collage students such as designs, inventions and contests and highly publicizing advanced typical entrepreneurship like Wang Lingguang who won the "May $4^{\text {th }}$ Youth Medal" in 2013, while implementing the platform of innovation and entrepreneurship. Constructing a good platform, choosing a good example and guiding their forward march for the students who have dreams of innovation and entrepreneurship, so it should be providing a better environment for them. 


\section{Conclusion and Prospect}

It needs to explore and deepen the education of innovation and entrepreneurship. With connotative development as a guide to reinforce education reform, with the teaching troop construction as a basement to promote the cooperation of collage and enterprise, with the fund operation as a guarantee to implement innovation and entrepreneurship services, with the activity platform construction of innovation and entrepreneurship education as a support to facilitate development of campus culture with characteristics of innovation and entrepreneurship. In the process of "4D" interaction mode, it is crucial that grasp the key role of tutors to promote innovation quality of college students and to bring the initiative of all quarters into play by establishing fund operation mode of college-enterprise cooperation. So that realizing the combination of the education of innovation and entrepreneurship, quality education and professional education. "Trinity" model is based on the education needs of innovation and entrepreneurship in collage students, it focus on the reform of mode of teaching in innovation and entrepreneurship education and it also can develop appropriate course system to cultivate students' innovation quality. Through teachers' training and collage-enterprise cooperation to reinforce the tutors' construction of innovation and entrepreneurship. Moreover, it also through educational development foundation of innovation and entrepreneurship to take advantages of course platform of innovation and entrepreneurship, practice platform, competitive platform, campus culture platform. As a result, it improves the conjunction of education of innovation and entrepreneurship and professional education and motivates students' aggressive, initiative and creativity. It inspires innovative thinking and entrepreneurial consciousness of students, and promotes their aptitude of creation and entrepreneurial abilities. There are lots of discussions and studies of education of innovation and entrepreneurship, however, education of innovation and entrepreneurship in different majors and different academic backgrounds should adopt to collage their own characteristics. It is necessary to set up an education system of innovation and entrepreneurship with flexible mechanism, reasonable operation and outstanding effect. Therefore, integrating entrepreneurial education resources to a characteristic specialty with combination of education of innovation and entrepreneurship, quality education and professional education, implementing reforms of models of talent cultivating and reforming the curriculum system. Proving an excellent environment for the establishing of "engineering" tutors and ensure they not only have high teaching and research qualities and innovation spirits, but also have rich coaching capabilities in entrepreneurship and practice abilities. Cultivating students' innovative abilities and stirring up their enthusiasm by making great efforts to carry out entrepreneurial education activities, such as creating innovation and entrepreneurship courses platform, competitive platform, practice platform and campus culture platform. Arousing the whole society participate in and build up matching funding system of innovation and entrepreneurship education. Besides, highlighting the leading role of government education sectors is also important. Strengthening collage-enterprise cooperation to establish talent incubators like pioneer park and high-tech industry cluster which provided by both parties. Making the curriculum modular, the teaching troop "engineered", the platform construction diversified, and production-learning-study integrative in education system of innovation and entrepreneurship. It is different form traditional higher education model,"trinity" opens and interacts various dynamics and actively participate in rather than passively. It mobilizes superiority resources from aspects to devote great efforts to the education of innovation and entrepreneurship, to realizing horizontal association of education in innovation and entrepreneurship, professional and quality educations. The whole situation of "trinity" presents omnibearing, multichannel and three-dimensional characteristics, it laying the foundation of developing education of innovation 
and entrepreneurship in collage and improving the overall qualities of students.

\section{References}

[1] Liu Changhong, Li Xiaohui, Li Gang,Yue Qingrong, Ren Yonggong. Practice and Exploration of Innovation and Entrepreneurship Training Programme for College Students [J]. Research and Exploration in Laboratory, 2014, 05: 163- 166.

[2] Wang Qiong, Sheng Dece, Chen Xuemei. The Education of Innovation and Entrepreneurship Driven by Project for Collage Students [J]. Experimental Technology and Management, 2013, 06: 99- 101.

[3] Tang Genli, Wang Yanbo. Exploration of Cultivation Path of Innovation and Entrepreneurship Ability for College Students [J]. Journal of Sichuan University of Science and Engineering (Philosophy and Social Sciences), 2011,03: 76- 79.

[4] Cao Jianhui, Zhou Hebing, Luo Yifan. Education Mode of Innovation and Entrepreneurship in College Students [J]. Research and Exploration in Laboratory, 2010, 08: 195- 198.

[5] Liu Guang. Research of Support Construction of Innovation and Entrepreneurship in College Students [J]. Science and Technology Progress and Policy, 2015, 23: 151- 155. 